\title{
Cotyledon persistence and seedling growth in fluted Pumpkin (Telfairia occidentalis Hook. F.)
}

\author{
Ayobola Moninuola Abosede SAKPERE ${ }^{1 *}$, Sunday Adesola AJAYI ${ }^{2}$ and \\ Adekunle Ajayi ADELUSI ${ }^{1}$ \\ ${ }^{I}$ Department of Botany, Obafemi Awolowo University, Ile - Ife, Nigeria. \\ ${ }^{2}$ Department of Crop Production and Protection, Obafemi Awolowo University, Ile - Ife, Nigeria. \\ *Corresponding author, E-mail: aasakpere@oauife.edu.ng ; asakpere@yahoo.com; Tel: 2348034033610
}

\begin{abstract}
Photosynthetic activity of exposed cotyledons of Telfairia occidentalis during seed germination and the growth of seedlings with removed or attached cotyledons were investigated. The experiment investigated how early cotyledon removal affects seedling growth. Seedlings from seeds germinated in light and those germinated in the dark were compared four weeks after germination. The effects of removal of cotyledons on seedling growth were also investigated with cotyledons removed at different times and from different seed sizes in order to assess the effect of time of removal and seed sizes on seedling growth. Biomass accumulation of the different plant parts, number of leaves and root/shoot ratio were used to assess the relative importance of cotyledon photosynthesis and cotyledon storage reserves to seedling growth. The cotyledons which are predominantly for storage were found to have a minimal photosynthetic function. Telfairia seedling biomass was significantly reduced $(\mathrm{P}<0.05)$ by removal of the cotyledon. Seed size and morphotype influenced the effect of cotyledon removal on seedling growth. The time of cotyledon removal affected all growth parameters negatively with greatest effect on removal at the first week of growth. Cotyledon reserves support seedling growth of Telfairia occidentalis, and ability to cope with loss of cotyledon is affected by factors such as seed size, morphotype and time of removal.

(C) 2015 International Formulae Group. All rights reserved.
\end{abstract}

Keywords: Storage reserves, cotyledon removal, hypogeal, morphotype, Telfairia occidentalis.

\section{INTRODUCTION}

Cotyledons exert a great influence on seedling development and growth and their contribution to early seedling development defines development strategy ( $\mathrm{Yi}$ and Liu, 2014). Cotyledons contribute to a young seedling's energy and nutrient demand either as photosynthetic or as reserve organs until the first true leaf becomes a significant source of assimilates (Kitajima, 2003; Zheng et al., 2011). Species with leaf-like photosynthetic cotyledons start to depend on light availability earlier than those with non-photosynthetic storage cotyledons, which have to wait for the development of the first leaves (Santos and Bukeridge, 2004).

Telfairia occidentalis Hook F., commonly called fluted pumpkin, is one of the vegetables native to Nigeria and found in the moist coastal areas of West Africa (Ajayi et al., 2007; Odiaka et al., 2008). It belongs to 
the family Cucurbitaceae. The highly nutritious leaves and seeds of $T$. occidentalis make it one of the three most important and widely eaten vegetables in West Africa (Abiose, 1999). The propagation of Telfairia plants is presently accomplished mainly by seeds. Although members of the family Cucurbitaceae undergo epigeal germination; the case is different for T. occidentalis. Fluted pumpkin germination is hypogeal and the cotyledons are normally buried in the soil. It is creamy yellow in colour and persistent. However, when exposed to light either in vivo or in vitro, the colour of fluted pumpkin cotyledon changes to green (Ajayi et al., 2006) just like the cotyledons of citrus seeds which have been confirmed to be photosynthetically functional when exposed to light (Rascio and Casadoro, 1988). It is not known if fluted pumpkin cotyledons are photosynthetically functional in light and whether or not they can contribute to the growth of its seedlings.

Seeds of Telfairia occidentalis are massive and consequently substantial amounts of seed biomass, largely cotyledons, are retained after shoot formation. Seedling physiology can be influenced by seed size or post-germination seed removal (Kennedy et al., 2004). Several ecologists have argued that the biomass remaining in cotyledons provides a reserve that can be used for growth and survival of seedlings in the presence of stress factors like low light, frequent shoot destruction, and strong competition (Kabeya and Sakai, 2003). However, the effect of post-germination seed/cotyledon removal appears to be species dependent because while post-germination seed/cotyledon removal had no effect on seedling growth in some species (Yi and Liu, 2014), it caused a significant decrease in others (Garcia-Cebrian et al., 2003). The aim of the present study was to investigate if Telfairia occidentalis cotyledon storage reserves and cotyledon greening influence seedling growth and physiology.

\section{MATERIALS AND METHODS}

Freshly harvested fruits of $T$. occidentalis were used for the study. To investigate the photosynthetic activity of exposed cotyledons after seed germination, eighty (80) seeds from the same fruit were collected and divided into four equal lots. Twenty (20) of the seeds were planted buried in vermiculite, twenty (20) were planted in vermiculite with the cotyledon half buried, twenty (20) were planted buried in top soil and the remaining twenty (20) were planted in top soil with the cotyledon half buried.

After four weeks, each seedling was uprooted and cut at the point of attachment to the cotyledon. Harvested seedlings were gently rinsed in water to remove remnants of the substratum, they were separated into leaves, stem and roots and thereafter oven dried at $80{ }^{\circ} \mathrm{C}$ for two days. The leaf, stem, and root of each seedling were then weighed. Chlorophyll content of cotyledon was extracted in acetone and quantitatively determined using the method of Coombs et al. (1985).

In order to determine the influence of seed reserves on seedling growth, seedlings with removed or attached cotyledons were compared. In all the treatments, the effect of cotyledon removal was investigated thus, seedlings were uprooted and the cotyledons excised. The seedlings were thereafter replanted and allowed to grow for four weeks before harvesting. Harvested seedlings were gently rinsed in water to remove soil, separated into leaf, stem, and root and then oven dried at $80{ }^{\circ} \mathrm{C}$ for two days. The leaf, stem, and root of each seedling were then weighed. The control seedlings were seedlings of the same age in which cotyledons had not been removed.

The effect of cotyledon removal at different stages of development of seedling growth was investigated by removing the cotyledon on a weekly basis for three weeks. In another separate experiment, cotyledons 
were removed at the $2^{\text {nd }}, 4^{\text {th }}, 6^{\text {th }}$ and $8^{\text {th }}$ leaf stages of growth. At each sampling, five seedlings were utilized. Similarly, the experiment was repeated for distinct seed sizes and seedling morphotypes. On the basis of size, seeds were categorized as small when seed weight was $5.9-10.9 \mathrm{~g}$, length ranged from $3.2 \mathrm{~cm}-4.2 \mathrm{~cm}$ and breadth ranging from $3.1 \mathrm{~cm}-4.5 \mathrm{~cm}$ ). They were categorized as large when seed weight was in the range $11-27 \mathrm{~g}$, length ranging from $4.2 \mathrm{~cm}-4.6 \mathrm{~cm}$ and breadth ranging from $4.7 \mathrm{~cm}-5.0 \mathrm{~cm}$ ). On the basis of morphotypes, 2 categories were distinct narrow-leaf morphotypes (narrow leaves with long internodes) and broad-leaf morphotypes (broad leaves with shorter internodes).

\section{Statistical analysis}

The results were subjected to analysis of variance and means were separated with Duncan's multiple range test (DMRT), using Statistical Analysis Software (SAS) version 9.2 .

\section{RESULTS}

Photosynthetic activity of exposed cotyledons after seed germination

Exposed cotyledon turned green while those buried did not. Chlorophyll was detected only in exposed and green cotyledons but not in buried cotyledons that did not change colour (Table 1). However, within the limit of the experiment, differences in seedling traits of seeds planted with cotyledons exposed and those with cotyledons buried were negligible irrespective of whether planted in soil or in vermiculite (Table 2).

\section{Influence of seed reserves on seedling growth}

Cotyledon removal significantly reduced seedling growth and biomass at all stages of removal $(\mathrm{P}<0.05)$. All seedling parameters, number of leaves, length of vine, leaf dry weight, vine dry weight and root dry weight were significantly $(\mathrm{P}<0.05)$ reduced. Timing of cotyledon removal affected all growth parameters negatively and the greatest effect was noticed when removal was done at the first week of growth and at the 2-leaf stage. The least effect occurred at the 8-leaf stage (Tables 3 and 4).

When the cotyledons were removed at the 2-leaf stage of the seedling, percentage reduction in seedling biomass compared to the control (leaf dry weight-96\%, vine dry weight-93\% and root dry weight-72\%) was higher relative to percentage reduction of seedling biomass for seedlings in which cotyledon was removed at the 8-leaf stage (leaf dry weight-53\%, vine dry weight $-53 \%$ and root dry weight-36\%). Likewise, percentage reduction in seedling biomass for plants with cotyledon removed one week after germination (leaf dry weight- $85 \%$, vine dry weight- $85 \%$ and root dry weight-80\%) was higher than those in which cotyledon was removed three weeks after germination (leaf dry weight $-85 \%$, vine dry weight $-85 \%$ and root dry weight-80\%) as compared to the control in which cotyledons were not removed (Figures 1 and 2). Cotyledon removal, irrespective of whether it was done by time or by leaf stage of development, affected seedling growth parameters negatively when compared with corresponding values for seedlings in which there was no cotyledon removal.

With regards to the effect of seed size and stage of cotyledon removal, there was no significant difference between the biomass of seedlings grown from big seeds and those from small seeds except with regards to length of vine, root dry weight and root/shoot ratio ( $r$ s ratio). Thus, no significant difference was observed between the effect of cotyledon removal at the 2-leaf stage and at the 4 and 6- 
leaf stages except with regard to length of vine and root/shoot ratio (Table 7). However, seedlings grown from small seeds had smaller percentage reduction in biomass compared to the control than seedlings grown from big seeds (Table 5). With regards to morphotypes, narrow-leaf morphotypes with removed cotyledons had higher percentage reduction in seedling biomass than broad-leaf morphotypes with removed cotyledons (Table 6). There were significant differences $(\mathrm{P}<0.05)$ between the biomass of narrow-leaf seedlings and broad-leaf seedlings. With regards to the effect of morphotype and time of cotyledon removal, there were significant reductions in value for all seedling parameters especially for removal at the first and second week (Table 8).

Table 1: Characteristics of exposed and buried T. occidentalis seeds.

\begin{tabular}{lcc}
\hline & Colour & Chlorophyll content \\
\hline Buried & Cream - yellow & 0 \\
Exposed & Green & $0.38 \mu \mathrm{M} \mathrm{g}^{-1}$ \\
\hline
\end{tabular}

Table 2: Mean values for traits of four-week old T. occidentalis seedlings from buried and exposed seeds on different substrata.

\begin{tabular}{lcccccc}
\hline Factors & $\begin{array}{c}\text { Length of } \\
\text { vine }\end{array}$ & $\begin{array}{c}\text { Leaf dry } \\
\text { weight }\end{array}$ & $\begin{array}{c}\text { Vine dry } \\
\text { weight }\end{array}$ & $\begin{array}{c}\text { Shoot dry } \\
\text { weight }\end{array}$ & $\begin{array}{c}\text { Root dry } \\
\text { weight }\end{array}$ & $\begin{array}{c}\text { Root/Shoot } \\
\text { ratio }\end{array}$ \\
\hline $\begin{array}{l}\text { Position } \\
\text { Buried }\end{array}$ & $56.22^{\mathbf{A}}$ & $1.54^{\mathbf{A}}$ & $1.0^{\mathbf{A}}$ & $2.53^{\mathbf{A}}$ & $0.76^{\mathbf{A}}$ & $0.25^{\mathbf{A}}$ \\
Exposed & $57.17^{\mathbf{A}}$ & $1.57^{\mathbf{A}}$ & $1.03^{\mathbf{A}}$ & $2.60^{\mathbf{A}}$ & $0.90^{\mathbf{A}}$ & $0.26^{\mathbf{A}}$ \\
\hline Medium type & & & & & \\
Soil & $58.16^{\mathbf{A}}$ & $1.60^{\mathbf{A}}$ & $1.06^{\mathbf{A}}$ & $2.66^{\mathbf{A}}$ & $0.76^{\mathbf{A}}$ & $0.26^{\mathbf{A}}$ \\
Vermiculite & $55.20^{\mathbf{A}}$ & $1.51^{\mathbf{A}}$ & $1.0^{\mathbf{A}}$ & $2.47^{\mathbf{A}}$ & $0.72^{\mathbf{A}}$ & $0.25^{\mathbf{A}}$ \\
\hline \multicolumn{4}{l}{ Among factor types, values with the same superscript letters along columns are not significantly different at P> 0.05.}
\end{tabular}

Table 3: Effect of growth stage at which cotyledons were removed on Telfairia occidentalis seedlings four weeks after removal.

\begin{tabular}{lccccc}
\hline Leaf stage & NOL & $\begin{array}{c}\text { LV } \\
(\mathbf{c m})\end{array}$ & $\begin{array}{c}\text { LDW } \\
(\mathbf{g})\end{array}$ & $\begin{array}{c}\text { VDW } \\
(\mathbf{g})\end{array}$ & $\begin{array}{c}\text { RDW } \\
(\mathbf{g})\end{array}$ \\
\hline CONTROL & $31.4^{\mathrm{A}}$ & $242.7^{\mathrm{A}}$ & $4.7^{\mathrm{A}}$ & $3.2^{\mathrm{A}}$ & $1.1^{\mathrm{A}}$ \\
2-LEAF & $11.0^{\mathrm{D}}$ & $19.2^{\mathrm{E}}$ & $0.2^{\mathrm{D}}$ & $0.2^{\mathrm{F}}$ & $0.3^{\mathrm{D}}$ \\
4-LEAF & $11.8^{\mathrm{D}}$ & $50.8^{\mathrm{DE}}$ & $0.5^{\mathrm{CD}}$ & $0.4^{\mathrm{EF}}$ & $0.3^{\mathrm{D}}$ \\
6-LEAF & $16.6^{\mathrm{DC}}$ & $97.8^{\mathrm{DC}}$ & $1.5^{\mathrm{BCD}}$ & $1.0^{\mathrm{EDF}}$ & $0.6^{\mathrm{C}}$ \\
8-LEAF & $21.6^{\mathrm{BC}}$ & $140.4^{\mathrm{BC}}$ & $2.2^{\mathrm{BC}}$ & $1.5^{\mathrm{EDC}}$ & $0.7^{\mathrm{BC}}$
\end{tabular}

Among factor types, values with the same superscript letters along columns are not significantly different at $\mathrm{P}>0.05$. LV - Length of Vine; LDW - Leaf Dry Weight; VDW - Vine Dry Weight; SDW - Shoot Dry Weight; RDW - Root Dry Weight; R/S - Root/Shoot Ratio; NOL - Number of Leaves. 
Table 4: Effect of age at which cotyledons were removed on shoot and root growth of Telfairia occidentalis seedlings.

\begin{tabular}{lccccc}
\hline Weeks & NOL & $\begin{array}{c}\text { LV } \\
(\mathbf{c m})\end{array}$ & $\begin{array}{c}\text { LDW } \\
(\mathbf{g})\end{array}$ & $\begin{array}{c}\text { VDW } \\
(\mathbf{g})\end{array}$ & $\begin{array}{c}\text { RDW } \\
(\mathbf{g})\end{array}$ \\
\hline Control & $24.0^{\mathrm{A}}$ & $201.1^{\mathrm{A}}$ & $1.3^{\mathrm{A}}$ & $2.0^{\mathrm{A}}$ & $1.0^{\mathrm{A}}$ \\
Week 1 & $8.8^{\mathrm{D}}$ & $38.0^{\mathrm{D}}$ & $0.2^{\mathrm{E}}$ & $0.3^{\mathrm{C}}$ & $0.2^{\mathrm{C}}$ \\
Week 2 & $12.8^{\mathrm{C}}$ & $88.3^{\mathrm{C}}$ & $0.4^{\mathrm{D}}$ & $0.6^{\mathrm{C}}$ & $0.3^{\mathrm{BC}}$ \\
Week 3 & $15.0^{\mathrm{CB}}$ & $160.2^{\mathrm{B}}$ & $0.8^{\mathrm{C}}$ & $1.4^{\mathrm{B}}$ & $0.6^{\mathrm{BA}}$ \\
\hline
\end{tabular}

Among factor types, values with the same superscript letters along columns are not significantly different at $\mathrm{P}>$ 0.05. LV - Length of Vine; LDW - Leaf Dry Weight; VDW - Vine Dry Weight; SDW - Shoot Dry Weight; RDW - Root Dry Weight; R/S - Root - Shoot Ratio; NOL - Number of Leaves;

Table 5: Effect of seed size on percentage reduction in biomass of seedlings of Telfairia occidentalis with cotyledon removal at different leaf stages.

\begin{tabular}{lcc}
\hline Leaf stages & Small seeds & Large seeds \\
\hline 2-LEAF & 86 & 72 \\
4-LEAF & 81 & 94 \\
6-LEAF & 63 & 80 \\
8-LEAF & 49 & 87 \\
\hline
\end{tabular}

Table 6: Effect of morphotype on percentage reduction in biomass of seedlings of Telfairia occidentalis with cotyledon removal at different ages.

\begin{tabular}{lcc}
\hline Weeks & Narrow leaves & Broad leaves \\
\hline Week 1 & 81 & 50 \\
Week 2 & 68 & 35 \\
Week 3 & 29 & 17 \\
\hline
\end{tabular}

Table 7: Effect of seed size and stage of cotyledon removal on shoot and root growth of Telfairia occidentalis seedlings traits four weeks after removal.

\begin{tabular}{lccccccc}
\hline Factor & NOL & LV & LDW & VDW & RDW & SDW & R/S \\
\hline Seed size & & & & & & \\
Big & $23.75^{\mathrm{A}}$ & $202.82^{\mathrm{A}}$ & $2.72^{\mathrm{A}}$ & $2.03^{\mathrm{A}}$ & $0.56^{\mathrm{B}}$ & $4.75^{\mathrm{A}}$ & $0.20^{\mathrm{B}}$ \\
Small & $22.52^{\mathrm{A}}$ & $149.89^{\mathrm{B}}$ & $2.50^{\mathrm{A}}$ & $1.73^{\mathrm{A}}$ & $0.73^{\mathrm{A}}$ & $4.23^{\mathrm{A}}$ & $0.28^{\mathrm{A}}$ \\
\hline Cotyledon & & & & & \\
Treatment & & & & & \\
Attached & $30.87^{\mathrm{A}}$ & $260.52^{\mathrm{A}}$ & $4.12^{\mathrm{A}}$ & $2.74^{\mathrm{A}}$ & $0.85^{\mathrm{A}}$ & $7.06^{\mathrm{A}}$ & $0.14^{\mathrm{B}}$ \\
Removed & $14.03^{\mathrm{B}}$ & $79.03^{\mathrm{B}}$ & $0.87^{\mathrm{B}}$ & $0.66^{\mathrm{B}}$ & $0.41^{\mathrm{B}}$ & $1.53^{\mathrm{B}}$ & $0.36^{\mathrm{A}}$ \\
\hline Leaf stage & & & & & \\
2-Leaf & $20.5^{\mathrm{B}}$ & $125.86^{\mathrm{C}}$ & $1.76^{\mathrm{B}}$ & $1.42^{\mathrm{B}}$ & $0.47^{\mathrm{C}}$ & $3.18^{\mathrm{B}}$ & $0.32^{\mathrm{A}}$ \\
4-Leaf & $22.24^{\mathrm{B}}$ & $160.77^{\mathrm{B}}$ & $2.04^{\mathrm{B}}$ & $1.53^{\mathrm{B}}$ & $0.58^{\mathrm{CB}}$ & $3.58^{\mathrm{B}}$ & $0.26^{\mathrm{A}}$ \\
6-Leaf & $21.75^{\mathrm{B}}$ & $177.36^{\mathrm{B}}$ & $2.66^{\mathrm{B}}$ & $1.93^{\mathrm{BA}}$ & $0.64^{\mathrm{B}}$ & $4.58^{\mathrm{B}}$ & $0.20^{\mathrm{B}}$ \\
8-Leaf & $27.0^{\mathrm{A}}$ & $227.46^{\mathrm{A}}$ & $3.70^{\mathrm{A}}$ & $2.50^{\mathrm{A}}$ & $0.85^{\mathrm{A}}$ & $6.20^{\mathrm{A}}$ & $0.19^{\mathrm{B}}$ \\
\hline Among factor types, values with the same superscript letters along columns are not significantly different at P> 0.05. \\
LV - Length of Vine; LDW - Leaf Dry Weight; VDW - Vine Dry Weight; SDW - Shoot Dry Weight; RDW - Root Dry \\
Weight; R/S - Root - Shoot Ratio; NOL - Number of Leaves. & & &
\end{tabular}


Table 8: Effect of plant morphotype and time of cotyledon removal on shoot and root growth of Telfairia occidentalis seedlings four weeks after removal.

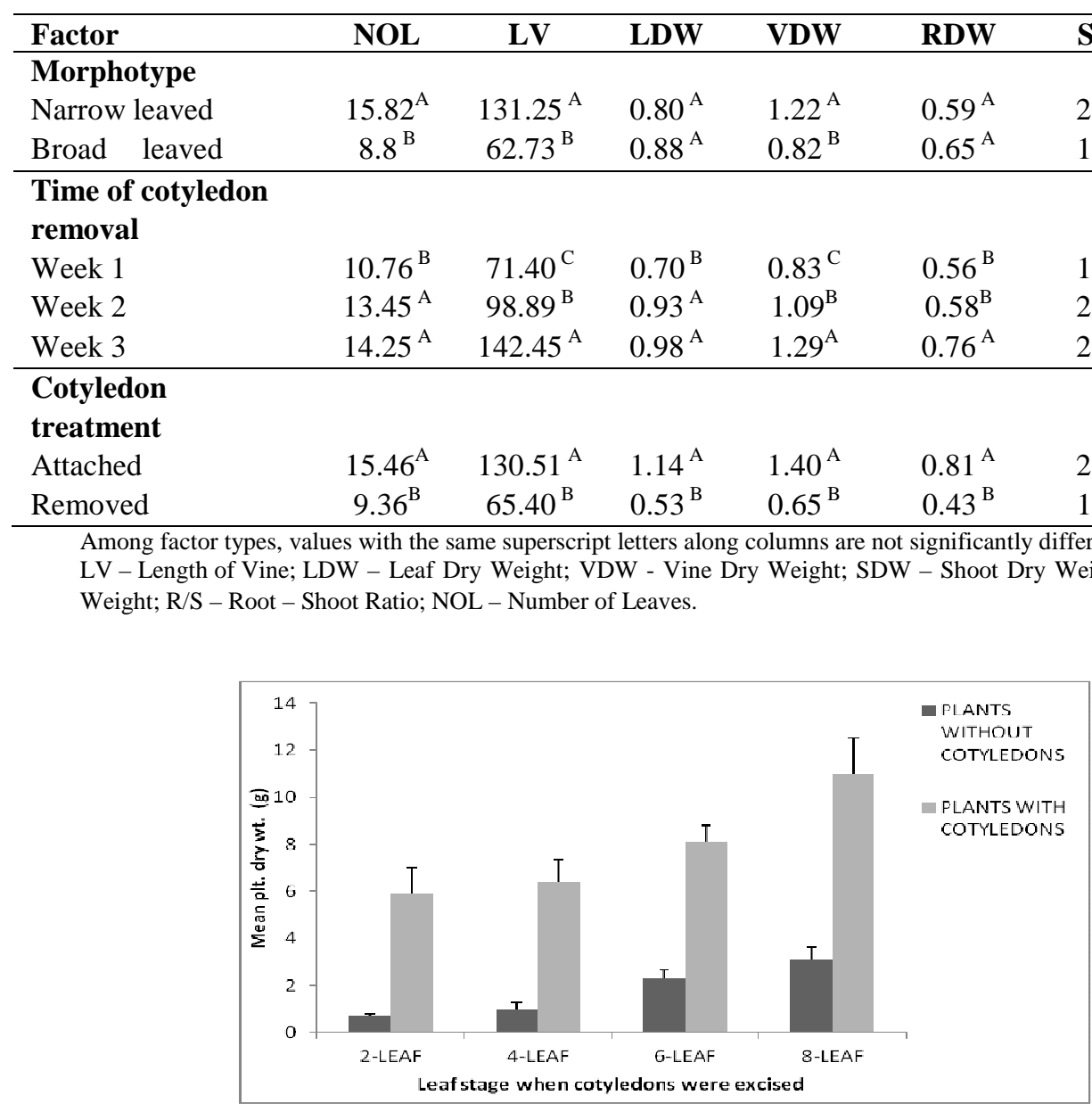

Figure1: The effect of cotyledon removal at different leaf stages on the mean $( \pm$ SE) dry weight biomass of Telfairia occidentalis four weeks after cotyledon removal.

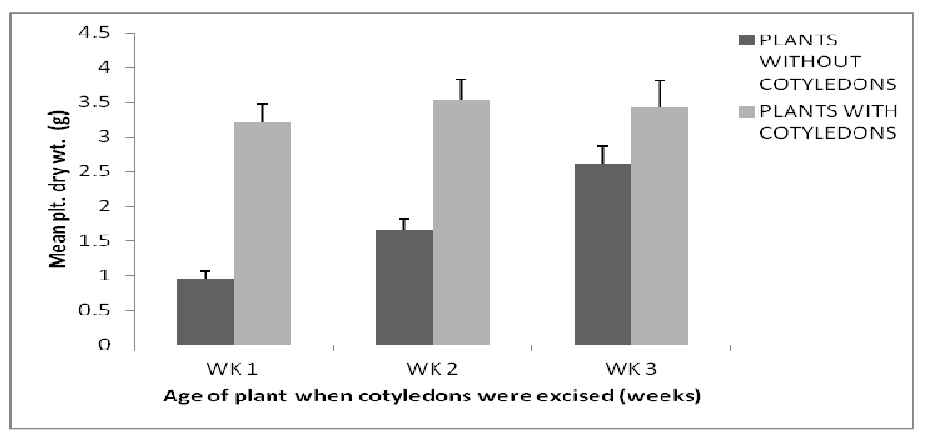

Figure 2: The effect of cotyledon removal at different plant ages on the mean $( \pm$ SE) dry weight biomass of Telfairia occidentalis four weeks after cotyledon removal. 


\section{DISCUSSION}

Seedling establishment stage is a critical phase in the life of a plant considering the fact that they are very vulnerable at this stage. The importance of cotyledon photosynthetic activity for early seedling growth has been stressed by several authors, particularly for woody plant species having seeds with epigeal germination (Kitajima, 2002; Bisognin et al., 2005; Zheng et al., 2011). However, hypogeal cotyledons of citrus fruits, in addition to the expected storage function, also become dark green developing a definite photosynthetic function in light, supported by well-organized chloroplasts (Rascio and Casadoro, 1988).

In this study, chlorophyll analysis revealed the presence of chlorophyll in the parts of hypogeal cotyledons of Telfairia occidentalis which turned green during germination under light suggesting the possibility of photosynthesis. Rascio and Casadoro (1988) reported that attainment of a green or darker green colour in all four species of citrus seeds during germination in light is strictly related to chlorophyll synthesis. They are therefore said to combine both storage and photosynthetic functions and are therefore regarded, in light, as "cotyledons important for seedling growth". Cotyledon photosynthesis in Telfairia, however, does not appear to play a predominant role in seedling development after the fourth week of growth. It is probable that whatever role the cotyledon photosynthesis plays may be earlier in the life of the seedling since it is not yet known when T. occidentalis seedlings transit from heterotrophic to autotrophic mode of life. One of the most important requirements for cotyledon photosynthesis is the support of the first leaf pair in epigeal germination. In this experiment however, seedlings were analyzed at the five leaf pair stage, by which time the advantages derived from cotyledon photosynthesis may no longer be evident due to leaf photosynthesis. However, Kitajima (2002) also reported that photosynthetic capacity per unit mass of $C$. latifolia cotyledons was low, unlike thinner dualfunction cotyledons that export their autotrophic carbon gain, the green, thick cotyledons of $C$. latifolia act primarily as storage organs and export negligible photosynthate, like those of Phaseolus spp.

Presence of attached cotyledons significantly affected number of leaves positively. The significantly higher number of leaves of seedlings with attached cotyledons may be due to mobilization of seed reserves for rapid development of leaves in young seedlings since existing literature indicates that energy reserves in cotyledons play an important role in supporting seedling development (Yi et al., 2015). It may also be due to the effect of the shock of uprooting, removing cotyledon and replanting on seedlings in which cotyledons were removed. The time and energy utilized in overcoming the shock and stabilizing could have impacted negatively on the seedlings affecting number of leaves produced in comparison to those of undisturbed seedlings with intact cotyledons. The findings in this study, clearly shows a significant reduction in biomass of seedlings with removed cotyledons when compared with seedlings with attached cotyledons even when the cotyledons were removed after the fourth leaf pair had been produced. The fact that there was no significant difference between the number of leaves at the two leaf and four leaf stages is indicative of growth arrest which in turn may be indicative of transition from one stage to another. The difference in number of leaves between the next two leaf stages was more than four times that of the two leaf and four leaf stages. The same trend occurred in leaf dry weight. Removal of cotyledon at the two leaf stage 
reduced elongation of vines by $92 \%$ while there was a $62 \%$ reduction in vine length between removal of cotyledon at the two leaf and four leaf stages. This suggests a very strong contribution of cotyledon to seedling development.

Detrimental effect of cotyledon removal even at the 4 pair (8- leaf) leaf stage may indicate that resources transferred from cotyledons to the seedling during this period must be important for survival, even after seedlings had developed fully expanded and photosynthetically active leaves. It is a pointer to the fact that the seedlings depend on the cotyledons for more than only carbohydrates even at this stage of growth. Kitajima et al. (2002) reported that seedlings of the most shade-tolerant species depended on seed reserves for the longest period for both energy and nitrogen. The duration of strict seed dependency for a given resource may vary among species in relation to four characteristics: seed size (total seed mass); seed quality (concentration of the focal resource); major function of cotyledons (whether cotyledons serve as photosynthetic or storage organs of seed reserves after germination); and inherent rate of seedling growth and development. The role of seed reserves in seedling nutrient dynamics may reveal different patterns of reserve dependence (Kennedy et al., 2004). Results obtained in this study suggest that the first two weeks of growth after emergence or the one pair (2-leaf) and two pairs (4- leaf) leaf stages of Telfairia seedlings are the critical stages at which cotyledon removal has the most detrimental effect on seedling growth.

The seed size and seedling biomass relationship observed in this study is contrary to the widespread view that initial seedling growth is positively correlated with seed size (Sousa et al., 2003; Iortsuun et al., 2008; Yi et al., 2015). Only length of vine and root characteristics were significantly affected by seed size with root dry weight of seedlings from bigger seeds significantly lower than those from smaller seeds and thereby translating to a significant difference in rootshoot ratio. This is as a result of the fact that the availability of a given resource in the seed is largely a function of the total seed mass (Kitajima and Fenner 2000) and when nutrient availability increases, plants allocate relatively less to their roots. This is consistent with a resource optimization hypothesis that increasing nutrient availability means that less effort is required to acquire this resource (Agren and Franklin 2003). Data from this study shows that seedlings from bigger seeds were more dependent on cotyledon than seedlings from smaller seeds. This is reflected in the higher percentage reduction in biomass by seedlings grown from bigger seeds, in which cotyledons have been removed. This implies that ultimately, seedlings derived from bigger seeds may be less able to cope with loss of cotyledons than seedlings derived from smaller seeds.

The narrow-leaf morphotype with lower root/shoot ratio however, was not able to cope with cotyledon loss as well as the broad-leaf morphotype with higher root/shoot ratio. Higher root/shoot ratio in broad-leaf morphotype was as a result of lower shoot dry weight, vines being significantly longer and leaves significantly more in narrow-leaf morphotypes. However, this number of leaves in narrow-leaf morphotypes, were not as efficient photosynthetically as the few and broader leaves of the broad-leaf morphotypes which were better able to cope with loss of cotyledons.

This study has demonstrated that Telfairia occidentalis seeds have predominantly storage cotyledons which can become photosynthetic when exposed to light and that cotyledon reserves support seedling 
growth. The study also elucidates the fact that ability to cope with loss of cotyledon is affected by factors such as seed size, morphotype and time of removal.

\section{REFERENCES}

Abiose S. 1999. Assessment of the extent of use of indigenous African foods, introduced foods and imported foods in hotels and other commercial eating places in southwestern Nigeria. In Africa's Natural Resources Conservation and Management Surveys, Baidu-Forson JJ (ed). UNU/INRA, Accra; 50-52.

Agren GI, Franklin O. 2003. Root-Shoot Ratios, optimization and Nitrogen Productivity. Annals of Botany, 92: 795800.

Ajayi SA, Berjak P, Kioko JI, Dulloo ME, Vodouhe RS. 2006. Observations on in vitro behaviour of the zygotic axes of fluted pumpkin. African Journal of Biotechnology, 5(15):1397-1404.

Ajayi SA, Dulloo ME, Vodouhe RS, Berjak P, Kioko JI. 2007. Progress on the conservation of fluted pumpkin (Telfairia occidentalis) germplasm. In Plant Genetic Resources and Food Security in West and Central Africa, Vodouhe SR, Atta-Krah K, Achigan-Dako GE, EyogMatig O, Avohou H (eds). Regional Conference, 26-30 April 2004, Biodiversity International: Rome, Italy; 78-88.

Bisognin DA, Velasquez L, Wildders I. 2005. Cucumber seedling dependence on cotyledonary leaves for early growth. Pesquisa Agropecuaria Brasileira Online 40(6): 531-539.

Coombs J, Hind G, Leegood RC, Tieszen LL, Vonshak A. 1985. Analytical Techniques. In Techniques in Bioproductivity and Photosynthesis ( $2^{\text {nd }}$ edn), Coombs J, Hall
DO, Long SP, Scurlock JMO (eds). Pergamon Press; 219-220.

Garcia-Cebrian F, Esteso-Martinez J, GilPelegrin E. 2003. Influence of cotyledon removal on early seedling growth in Quercus robur L. Ann. For. Sci., 60: 6973.

Iortsuun DN, Chia AM, Adeola AF. 2008. the effect of seed mass and cotyledon removal on the germination and growth of fluted pumpkin (Telfairia occidentalis Hook. F). Science World Journal, 3(1): 25-31.

Kabeya D, Sakai S. 2003. The role of roots and cotyledons as storage organs in early stages of establishment in Quercus crispula: a quantitative analysis of the non structural carbohydrate in cotyledons and roots. Annals of Botany, 92: 537545.

Kennedy PG, Hausmann NJ, Wenk EH, Dawson TE. 2004. The importance of seed reserves for seedling performance: an integrated approach using morphological, physiological, and stable isotope techniques. Oecologia, 141: 547554.

Kitajima K. 2002. Do shade-tolerant tropical tree seedlings depend longer on seed reserves? Functional growth analysis of three Bignoniaceae species, Functional Ecology, 16: 433-444.

Kitajima K. 2003. Impact of Cotyledon and Leaf Removal on Seedling Survival in Three Tree Species with Contrasting Cotyledon Functions. Biotropica, 35(3): 429-434.

Kitajima K, Fenner M. 2000. Ecology of seedling regeneration. In Seeds: The Ecology of Regeneration in Plant Communities, Fenner M (ed). CABI: New York; 331-360.

Odiaka NI, Akoroda MO, Odiaka EC. 2008. Diversity and production methods of 
fluted pumpkin (Telfairia occidentalis Hook F.); Experience with vegetable farmers in Makurdi, Nigeria. African Journal of Biotechnology, 7(8): 944-954.

Rascio N, Casadoro G. 1988. Cotyledon greening in hypogeal seeds of citrus fruits Journal of Ultrastructure and Molecular Structure Research, 101(1): 13-22.

Sousa WP, Kennedy PG, Mitchell B. 2003. Propagule size and predispersal damage by insects affect establishment and early growth of mangrove seedlings. Oecologia, 135: 564-575.
Yi XF, Liu CQ. 2014. Retention of cotyledons is crucial for re-sprouting of clipped oak seedlings. Sci. Rep., 4: 5145.

Yi X, Wang Z, Liu C, Liu G, Zhang M. 2015. Acorn cotyledons are larger than their seedlings' need: evidence from artificial cutting experiments. Sci. Rep., 5: 8112.

Zheng W, Wang P, Zhang HX, Zhou D. 2011. Photosynthetic characteristics of the cotyledon and first true leaf of castor (Ricinus communis L.) Australian Journal of Crop Science, 5(6): 702 -708. 